\title{
ABSORPTION OF GLUCOSE AND METHIONINE FROM THE HU- MAN INTESTINE; THE INFLUENCE OF THE GLUCOSE CONCENTRATION IN THE BLOOD AND IN THE INTESTINAL LUMEN
}

\author{
By ALVIN J. CUMMINS 1
}

\author{
(From the Department of Medicine, the New York Hospital-Cornell Medical Center, New \\ York, N. Y.)
}

(Submitted for publication June 11, 1952; accepted August 1, 1952)

\section{INTRODUCTION}

The inaccessibility of the absorbing surface of the small bowel and its blood supply has made studies of intestinal absorption difficult and has left large gaps in our knowledge of the fundamental mechanisms involved and the factors influencing them. Animal experimentation has provided the basis for much of what is known (1). The desirability of obtaining similar data in the human subject has led to many ingenious methods for the measurement of absorption in man. None of these, however, has proved entirely satisfactory. Studies of systemic blood concentrations of ingested materials reflect utilization, rate of storage, excretion, and circulatory competency as well as absorption. Recent methods using the sampling of "portal" blood from anastomotic abdominal vessels in cases of portal hypertension employ as subjects patients with cirrhotic livers, in which the effects of the portal hypertension on absorptive processes, and the extent and effect of dilution of intestinal venous blood with hepatic arterial blood are unknown (2-4). Balance studies require elaborate supervision, are expensive, and are inapplicable to the study of absorption of sugars, due to destruction from fermentation.

Various techniques using intubation of the human small bowel have provided a more direct approach to the subject (5-7). Disturbance of normal intestinal functioning has led to objections to several of these procedures (8). Nicholson and Chornock (9) seem to have devised the most physiologic of the intubation methods for the measurement of absorption. In their technique

1 Lewis Cass Ledyard, Jr. Fellow of the New York Hospital. Present Address: Gastrointestinal Section, Hospital of the University of Pennsylvania, Philadelphia, Pa. the material to be studied is dripped into the intestine, travels downstream with the normal bowel contents, and is aspirated below, loss beyond the point of aspiration being prevented by an occluding balloon. The advantages are normal admixture with intestinal contents, maintenance of normal ratio of volume of material to mucosal area, physiologic entrance of material into the bowel, lack of interference with normal peristalsis in the absorbing area, and a fairly sharp starting and stopping point. These authors reported the application of their method to the study of ascorbic acid absorption.

It has been our purpose in this investigation to study some additional phenomena of human intestinal absorption by the Nicholson-Chornock method, and to evaluate its use as an investigative tool. In this paper is presented our experience in studying the absorption of two different concentrations of glucose and methionine solutions from the upper small bowel of normal human subjects, and the effect of insulin-induced hypoglycemia and of hyperglycemia on the absorption rate.

\section{METHODS}

In place of a two-lumen tube with an additional small outer tube to control inflation of the balloon, as employed by Nicholson and Chornock, a single, three-lumen, size 16 French tube was used. The first lumen connected with the balloon, which was located on the end of the tube. The second lumen communicated with six aspiration holes, immediately proximal to the balloon. Forty-five centimeters proximal to these were located two additional holes which connected with the third lumen.

All subjects were intubated in the morning after an 8 hour fast. When the two most proximal (inlet) holes were in the midduodenum (as judged by fluoroscopy and the aspiration of bile-stained alkaline fluid) the tube was anchored to the nose and the test begun. The distal end of the tube with the balloon was now well into the upper jejunum. 
The subject was placed in the supine position and the balloon was inflated to a pressure of 25-30 centimeters of water as measured on a manometer which was provided with a float so that intestinal motility patterns could be kymographically recorded during the test. The solution to be used in the experiment was then allowed to drip into the proximal (inlet) holes in the duodenum at a rate of $10 \mathrm{cc}$. per minute, which simulates the normal entrance rate of material into the bowel from the stomach as determined by Karr and Abbott (10). The rate of infusion was controlled by a "Flowrator." 2 As the infusion was started, suction was applied to the outlet holes $45 \mathrm{cms}$. down the bowel and maintained by a pump at a negative pressure of $125 \mathrm{~cm}$. of water. Timings were made by stopwatch. After 30 minutes the infusion was stopped and the bottles changed on the suction lumen. Three 10 minute "wash" periods were then run, with an injection of $100 \mathrm{cc}$. of water or 33 per cent $\mathrm{Mg} \mathrm{SO}$, through the inlet holes at the beginning of each period, the aspirated samples being collected separately. This constituted one "absorption test." In 20 to 30 minutes a second complete test was carried out and, if any changes in the experimental conditions were desired (injection of insulin or intravenous glucose, for instance) they were introduced just prior to the start of the second test. It was thus possible to vary the conditions using the subject as his own control. At the end of the entire procedure the position of the tube was again verified fluoroscopically before removal.

In some tests it was desired to check on possible loss of the infusing solution past the occluding balloon. A fourlumen, size $18 \mathrm{~F}$ tube was used, constructed as above, with the fourth lumen connected to holes located distal to the balloon. In such tests constant suction was maintained on these openings during the entire procedure.

The substances used in the absorption tests were glucose and $d l$-methionine in solutions containing approximately either 1) 5 per cent glucose and 0.25 per cent methionine or 2) 10 per cent glucose and 0.50 per cent methionine. Approximate concentrations only were used because the magnitude of other errors inherent in the procedure did not seem to justify further refinement. In each case, however, the solutions were analyzed to determine their exact composition. Preliminary tests revealed no interference in the chemical determination of either of these substances by the other in the concentration ratios used.

When the tests were completed, all samples including the infusion solution were measured and analyzed for glucose by the colorimetric Folin-Wu method, and for methionine by the Hess and Sullivan modification (11) of the original McCarthy and Sullivan method. In certain cases the specimens during the methionine analysis gave turbid solutions, and these cases were discarded as yielding inaccurate results. In only a few cases a "blank" reading for methionine was given by a specimen of

2 Flowrator (Graubard-Peterson) manufactured by Fischer \& Porter Company, 350 Fifth Avenue, New York. pure intestinal juice obtained prior to beginning the test. This "blank" was then subtracted from the amounts contained in the specimens. In no case was there found a "blank" reading for glucose. When blood was analyzed for glucose, the micro method of Nelson (12) was used which employs capillary blood. The Klett photoelectric colorimeter was used for all determinations.

In calculating the results of the experiments the total amounts of material aspirated during the initial 30-minute infusion period and during the three 10-minute wash periods were substracted from the amount introduced in the first 30-minute period. The result is expressed as amount of material absorbed per 30 minutes.

The subjects studied were either healthy young male medical students, or patients from the wards of the New York Hospital without known gastrointestinal disease or alterations in metabolism. All had been taking a balanced diet in the days immediately preceding the tests and reported to the laboratory in the fasting state.

\section{OBSERVATIONS}

\section{Relation of intestinal motility to the sharpness of the end-point of the procedure}

Typical complete results for two representative tests are demonstrated in Table I. Only the figures for glucose are given for the sake of simplicity. In the first subject, T. M., 5 per cent glucose was studied and it will be seen that the washing procedures were quite effective in that all of the glucose was removed with the first wash, providing a fairly sharp "end-point" to the procedure. In the second subject, L. E., however, in which 10 per cent glucose was used, it will be seen that some glucose was still washed out with the final rinse. When calculating the amount absorbed per $30 \mathrm{~min}$ utes, there is the obvious error of glucose having been present on the absorbing mucosa for considerably longer, though in decreasing concentrations. Fortunately, over 75 per cent of our tests corresponded to the first type with fairly sharp end-points.

The reason for this delay in evacuating all the non-absorbed material in some of the tests does not seem to be due to the somewhat smaller bore suction tube used in place of the original NicholsonChornock model because, while their tube had a withdrawal capacity of $175 \mathrm{cc}$. per minute, ours had a capacity of $100 \mathrm{cc}$. per minute, well in excess of the possible rate of accumulation. Nor does it seem related to the use of water as a wash material in place of the recommended magnesium sulfate, which the original authors believed to cause 
TABLE I

Complete results of two representative tests of glucose absorption

\begin{tabular}{|c|c|c|c|c|c|}
\hline Subject & $\begin{array}{l}\text { Infusion } \\
\text { 1) Gluc. conc. } \\
\text { 2) Vol. } \\
\text { 3) Total gluc. }\end{array}$ & Fluid vol. aspirated & $\begin{array}{c}\text { Gluc. conc. in } \\
\text { aspirated samples }\end{array}$ & $\begin{array}{c}\text { Amount gluc. } \\
\text { aspirated }\end{array}$ & $\begin{array}{l}\text { Total gluc. } \\
\text { absorbed }\end{array}$ \\
\hline T. M. & $\begin{array}{l}\text { 1) } 5.30 \mathrm{gm} . \% \\
\text { 2) } \% \mathrm{cc} . \\
\text { 3) } 16.70 \mathrm{gm} .\end{array}$ & $\begin{array}{l}\text { 1) } 30 \mathrm{~min} .=325 \mathrm{cc} . \\
\text { 2) } 1 \mathrm{st} \text { wash }=113 \mathrm{cc} . \\
\text { 3) } 2 \mathrm{nd} \text { wash }=106 \mathrm{cc} . \\
\text { 4) } 3 \mathrm{rd} \text { wash }=85 \mathrm{cc} .\end{array}$ & $\begin{array}{l}\text { 1) } 2.46 \mathrm{gm} . \% \\
\text { 2) } 1.46 \mathrm{gm} . \% \\
\text { 3) } .04 \mathrm{gm} . \% \\
\text { 4) } .00 \mathrm{gm} . \%\end{array}$ & $\begin{array}{l}\text { 1) } 8.00 \mathrm{gm} . \\
\text { 2) } 1.65 \mathrm{gm} . \\
\text { 3) }- \\
\text { 4) }- \\
\text { Total } 9.65 \mathrm{gm} .\end{array}$ & $7.05 \mathrm{gm}$. \\
\hline L. E. & $\begin{array}{l}\text { 1) } 10.55 \mathrm{gm} . \% \\
\text { 2) } 296 \mathrm{cc} . \\
\text { 3) } 31.20 \mathrm{gm} .\end{array}$ & $\begin{array}{l}\text { 1) } 30 \mathrm{~min} . \\
\text { 2) } 1 \mathrm{st} \text { wash }=93 \mathrm{cc} . \\
\text { 3) } 2 \mathrm{nd} \text { wash }=77 \mathrm{cc} . \\
\text { 4) } 3 \mathrm{rd} \text { wash }=66 \mathrm{cc} .\end{array}$ & $\begin{array}{l}\text { 1) } 3.32 \mathrm{gm} . \% \\
\text { 2) } 3.72 \mathrm{gm} . \% \\
\text { 3) } 1.74 \mathrm{gm} . \% \\
\text { 4) } .30 \mathrm{gm} . \%\end{array}$ & $\begin{array}{l}\text { 1) } 4.65 \mathrm{gm} . \\
\text { 2) } 3.46 \mathrm{gm} . \\
\text { 3) } 1.34 \mathrm{gm} . \\
\text { 4) } .20 \mathrm{gm} . \\
\text { Total } 9.65 \mathrm{gm} .\end{array}$ & $21.55 \mathrm{gm}$. \\
\hline
\end{tabular}

a peristaltic rush down the bowel thus providing a rapid evacuation of unabsorbed material. With the method of simultaneously recording motility no evidence of increased peristalsis was found in those tests employing magnesium sulfate, and washing with water seemed to be just as satisfactory. Rather the differences in efficiency of washing are more closely related to differences in the spontaneous bowel motility at the time. Figure 1 shows the motility tracing obtained in the two tests on T. M. and L. E. Whereas that of T. M. was quite active, the motility of the bowel in L. E. was relatively sluggish. Evidently intestinal peristaltic activity is needed to "milk" the washing fluid down to the evacuation openings. It was possible to predict that one would obtain a "good" test or a "bad" one by watching the degree of motility being recorded.

\section{Possible loss of material past the occluding balloon}

In all experiments, a condom rubber balloon approximately 2 inches long, inflated to a pressure of 25 to $30 \mathrm{~cm}$. of water, was used. Abbott and Miller (6) have shown that under such conditions the small bowel lumen is effectively blocked. To check this further, four subjects were studied at the end of their absorption tests. Thin suspensions of barium were injected through the holes just proximal to the balloon and fluoroscopic observations were made for 30 minutes afterward. In no case was the barium seen to leak past the balloon. As an additional check, the four-lumen tube was used in eight subjects for a total of 16 absorption tests. Though suction was maintained during the entire procedure (in some of which intestinal motility was stimulated with drugs),
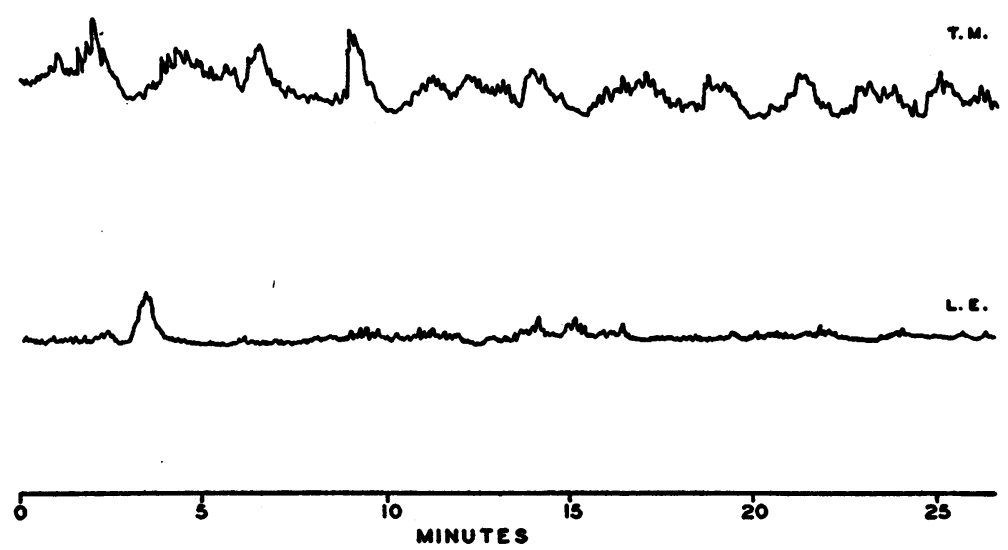

Fig. 1. Motrity Tracings proy the Sycall Intestine, Indicating Dimferences in Spontaneous Phasic Activity among Various Tests 

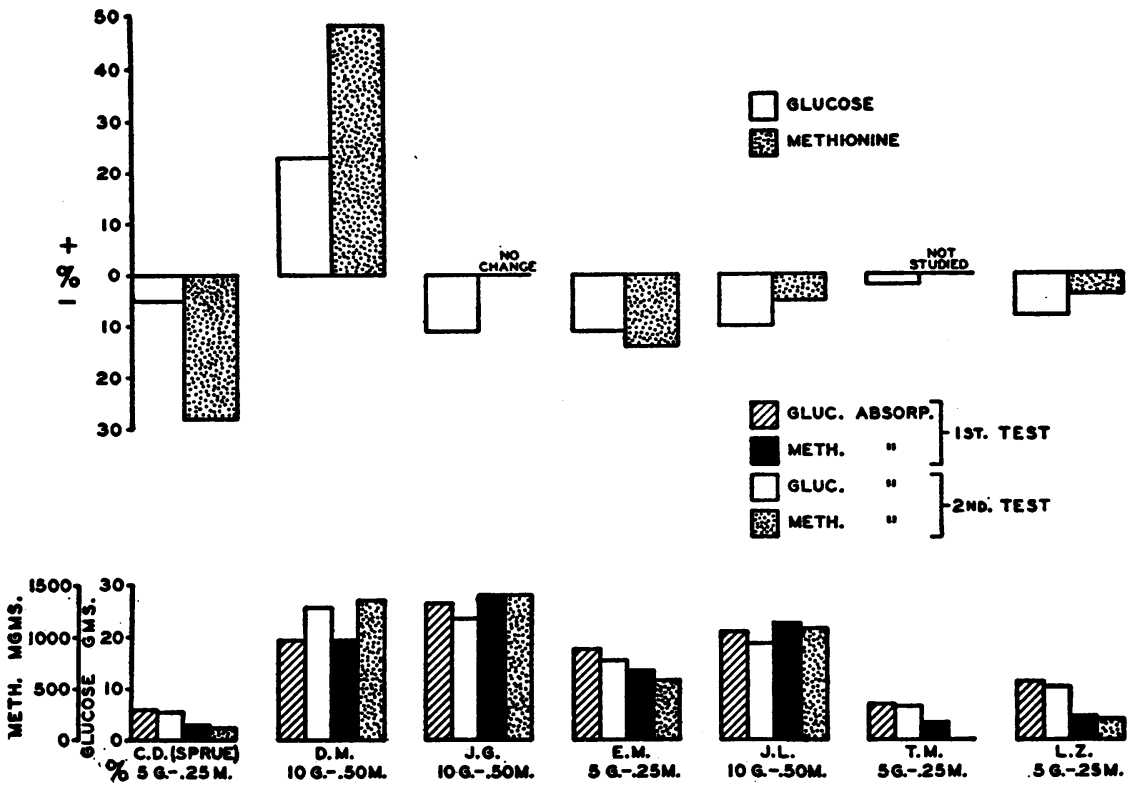

Fig. 2. Absolute Absorption Rates in Seven Subjects as Determined by Two Consecutively Performed Tests without Medication

Percentage of change between the two tests is indicated above.

no glucose or methionine was found in any of the fluids collected distal to the balloon. In addition, we had the opportunity of studying ileal absorption in one patient with an ileostomy. In this subject the distal end of the tube was located just proximal to the ileostomy, and throughout the absorption tests the ileostomy bag was kept in position. The contents of the bag remained free of glucose and methionine. Evidently the balloon provides an adequate block preventing loss of material past it.

\section{Difficulty in maintaining tube position in the bowel}

Fluoroscopic visualization of the tube before beginning the absorption test and again at the end of the procedure, demonstrated that, in a fair proportion of the cases, there was a tendency for the intestine to move up along the tube. The second observation often showed the tube tip down nearer the cecum, although that portion of it remaining outside the subject stayed the same, and the tube was firmly anchored. Evidently in some of the cases, the $45 \mathrm{~cm}$. length of intestine whose absorption rate was being studied did not remain always the same.

\section{Variability in the results of two absorption tests performed consecutively}

All tests on all subjects were run consecutively in duplicate. In seven subjects no attempt was made to alter conditions between the two tests in order to determine the reproducibility of results. The glucose and methionine absorption rates in these subjects are shown in Figure 2. The subject C. D. was a patient with sprue and his absorption figures will not be considered in the remainder of this paper. The greatest variation between two tests for glucose absorption is under 25 per cent and for methionine absorption, under 50 per cent. Most of the tests show considerably less variability. Thus, by studying the absorption rate in the same individual, and under the same circumstances, and within a short period after a previous study, the checks are gratifyingly close, considering the many potential sources of error. Six of the seven subjects show an absorption rate in the second test below that in the first. That this might be due to the fact that the subject approached the second test with blood levels of glucose and methionine higher than he had had in the preceding test, seems unlikely in view of subsequent studies of the effect of hyperglycemia. 
5. Difference in absorption rates with two different concentrations of glucose and methionine

Absorption rates were studied for 5 per cent glucose and 0.25 per cent methionine in 16 and 15 instances respectively in nine subjects, and for 10 per cent glucose and 0.50 per cent methionine in 12 instances in eight subjects. The results are shown in Tables II-V. The range of amounts absorbed of both test substances is considerable. However, the difference in the mean absorption values for 5 per cent and 10 per cent glucose ( 6.2 $\mathrm{gm}$.) is 3.26 times the standard error of the difference, and the difference in means for the two concentrations of methionine ( $586 \mathrm{mgm}$.) is 4.92 times its standard error. For a sample of this size the difference in absorption rate between the two concentrations of both substances thus seems to be a real one and substantiates the view that the in-

TABLE II

Absorption rates for approximately 5 per cent glucose

\begin{tabular}{|c|c|c|c|c|}
\hline Subject & $\begin{array}{c}\begin{array}{c}\text { Conc. test } \\
\text { sol. } \\
\text { gm. } \%\end{array} \\
\end{array}$ & $\begin{array}{l}\text { Gm. gluc. } \\
\text { absorbed } \\
30 \mathrm{~min} .\end{array}$ & $\begin{array}{l}\text { \% Gluc. } \\
\text { absorbed }\end{array}$ & $\begin{array}{c}\begin{array}{c}\text { Gluc. } \\
\text { absorption } \\
\text { coefficient* }\end{array} \\
\end{array}$ \\
\hline E. M. & 6.14 & $\begin{array}{l}17.7 \\
15.7\end{array}$ & $\begin{array}{l}98 \\
93\end{array}$ & $\begin{array}{l}8.5 \\
7.5\end{array}$ \\
\hline H. R. & 6.38 & 13.4 & 68 & 6.6 \\
\hline T. M. & 5.30 & $\begin{array}{l}7.1 \\
6.9 \\
\end{array}$ & $\begin{array}{l}42 \\
45\end{array}$ & $\begin{array}{l}3.6 \\
3.6\end{array}$ \\
\hline P.S. & 6.00 & 17.9 & 88 & 9.4 \\
\hline A. B. & 5.70 & $\begin{array}{l}13.1 \\
14.9 \\
\end{array}$ & $\begin{array}{l}73 \\
87\end{array}$ & $\begin{array}{l}8.8 \\
9.9\end{array}$ \\
\hline R. Q. & 5.46 & $\begin{array}{l}17.7 \\
17.0\end{array}$ & $\begin{array}{l}86 \\
96\end{array}$ & $\begin{array}{l}8.8 \\
8.4\end{array}$ \\
\hline H. V. & 5.46 & $\begin{array}{l}10.1 \\
10.2\end{array}$ & $\begin{array}{l}59 \\
60\end{array}$ & $\begin{array}{l}5.7 \\
5.7\end{array}$ \\
\hline T. M. & 5.78 & $\begin{array}{l}12.5 \\
10.6\end{array}$ & $\begin{array}{l}74 \\
64\end{array}$ & $\begin{array}{l}6.4 \\
5.4\end{array}$ \\
\hline L. Z. & 5.46 & $\begin{array}{l}11.3 \\
10.4 \\
\end{array}$ & $\begin{array}{l}69 \\
64 \\
\end{array}$ & $\begin{array}{l}6.8 \\
6.2\end{array}$ \\
\hline \multicolumn{2}{|l|}{ Range } & $6.9-17.9$ & $42-98$ & $3.6-9.9$ \\
\hline \multicolumn{2}{|l|}{ Mean $(\overline{\mathrm{X}})$} & 12.9 & 73 & 7.0 \\
\hline \multicolumn{2}{|c|}{ Stan. dev. ( $(\sigma)$} & \pm 3.6 & & \pm 1.9 \\
\hline \multicolumn{2}{|c|}{ Coeff. of var. $\left(\frac{100 \sigma}{\bar{x}}\right)$} & $28 \%$ & & $27 \%$ \\
\hline \multicolumn{2}{|c|}{ Stan. error mean $\left(\sigma_{\overline{\mathbf{x}}}\right)$} & \pm .90 & & \pm .48 \\
\hline
\end{tabular}

* Absorption coefficient $=\mathrm{gm}$. absorbed $/ 30 \mathrm{~min} . / \mathrm{sq}$. meter body surface.
TABLE III

Absorption rates for approximately 10 per cent glucose

\begin{tabular}{|c|c|c|c|c|}
\hline Subject & $\begin{array}{l}\text { Conc. test } \\
\text { sol. } \\
\text { gm. \% }\end{array}$ & $\begin{array}{l}\text { Gm. gluc. } \\
\text { absorbed } \\
30 \text { min. }\end{array}$ & $\begin{array}{l}\% \text { Gluc. } \\
\text { absorbed }\end{array}$ & $\begin{array}{l}\text { Gluc. } \\
\text { absorption } \\
\text { coefficient }\end{array}$ \\
\hline P.S. & 9.75 & 14.2 & 52 & 7.5 \\
\hline D. M. & 10.45 & $\begin{array}{l}19.6 \\
25.9\end{array}$ & $\begin{array}{l}70 \\
88\end{array}$ & $\begin{array}{r}9.7 \\
12.8\end{array}$ \\
\hline C. T. & 10.00 & 10.5 & 39 & 5.9 \\
\hline J. G. & 10.45 & $\begin{array}{l}26.6 \\
23.8\end{array}$ & $\begin{array}{l}94 \\
75\end{array}$ & $\begin{array}{l}13.3 \\
11.9\end{array}$ \\
\hline J. L. & 10.40 & $\begin{array}{l}21.1 \\
18.9\end{array}$ & $\begin{array}{l}64 \\
59\end{array}$ & $\begin{array}{l}11.2 \\
10.0\end{array}$ \\
\hline S. B. & 9.25 & 7.3 & 27 & 4.1 \\
\hline L. E. & 10.55 & $\begin{array}{l}21.6 \\
20.9\end{array}$ & $\begin{array}{l}69 \\
73\end{array}$ & $\begin{array}{l}14.1 \\
13.6\end{array}$ \\
\hline K. M. & 10.55 & 19.3 & 60 & 8.8 \\
\hline \multicolumn{2}{|l|}{ Range } & $7.3-26.6$ & $27-94$ & $4.1-14.1$ \\
\hline \multicolumn{2}{|l|}{$\operatorname{Mean}(\overline{\mathrm{X}})$} & 19.1 & 64 & 10.2 \\
\hline \multicolumn{2}{|c|}{ Stan. dev. $(\sigma)$} & \pm 5.8 & & \pm 3.2 \\
\hline \multicolumn{2}{|c|}{ Coeff. of var. $\left(\frac{100 \sigma}{\bar{x}}\right)$} & $30 \%$ & & $31 \%$ \\
\hline \multicolumn{2}{|c|}{ Stan. error mean $\left(\sigma_{\bar{x}}\right)$} & \pm 1.67 & & \pm .92 \\
\hline
\end{tabular}

testinal mucosa can absorb glucose and methionine at a greater rate from 10 per cent and 0.50 per cent solutions than from 5 per cent and 0.25 per cent concentrations respectively.

In calculating "absorption coefficients" an attempt was made to reduce the scatter of the results by reducing all values to amounts absorbed per 30 minutes per square meter of body surface. The results seem to indicate, however, that no reduction in variability is achieved. The variability of the "absorption coefficients" is quite similar to that of the uncorrected figures. Apparently variation in body surface area is not one of the factors contributing to the scatter of the absorption rates.

In the range of concentrations studied, the percentages of glucose and methionine absorbed are roughly the same. That this correlation is not due to loss or lack of complete recovery of unabsorbed material, is demonstrated by the evidence that loss past the balloon does not occur and by the fact that, in all cases, the three wash periods effectively removed all unabsorbed residue, though 
TABLE IV

Absorption rates for approximately 0.25 per cent methionine

\begin{tabular}{|c|c|c|c|c|}
\hline Subject & $\begin{array}{c}\text { Conc. test } \\
\text { sol. } \\
\text { gm. \% }\end{array}$ & $\begin{array}{l}\text { Mgm. meth. } \\
\text { absorbed } \\
30 \text { min. }\end{array}$ & $\begin{array}{l}\text { \% meth. } \\
\text { absorbed }\end{array}$ & $\begin{array}{l}\text { Meth. } \\
\text { absorption } \\
\text { coefficient* }\end{array}$ \\
\hline E. M. & .26 & $\begin{array}{l}684 \\
589\end{array}$ & $\begin{array}{l}89 \\
82\end{array}$ & $\begin{array}{l}326 \\
281\end{array}$ \\
\hline H. R. & .30 & 512 & 55 & 251 \\
\hline T. M. & .24 & 186 & 24 & 96 \\
\hline P.S. & .24 & 476 & 59 & 250 \\
\hline A. B. & .26 & $\begin{array}{l}583 \\
578\end{array}$ & $\begin{array}{l}71 \\
74\end{array}$ & $\begin{array}{l}389 \\
386\end{array}$ \\
\hline R. Q. & .24 & $\begin{array}{l}696 \\
728\end{array}$ & $\begin{array}{l}77 \\
93\end{array}$ & $\begin{array}{l}345 \\
361\end{array}$ \\
\hline H. V. & .20 & $\begin{array}{l}298 \\
323\end{array}$ & $\begin{array}{l}48 \\
52\end{array}$ & $\begin{array}{l}167 \\
180\end{array}$ \\
\hline T. M. & .26 & $\begin{array}{l}307 \\
396\end{array}$ & $\begin{array}{l}41 \\
53\end{array}$ & $\begin{array}{l}157 \\
203\end{array}$ \\
\hline L. Z. & .20 & $\begin{array}{l}231 \\
222\end{array}$ & $\begin{array}{l}39 \\
38\end{array}$ & $\begin{array}{l}138 \\
133\end{array}$ \\
\hline \multicolumn{2}{|l|}{ Range } & $186-728$ & 24-93 & $96-389$ \\
\hline \multicolumn{2}{|l|}{ Mean $(\overline{\mathrm{X}})$} & 454 & 60 & 244 \\
\hline \multicolumn{2}{|c|}{ Stan. dev. $(\sigma)$} & \pm 172 & & \pm 99 \\
\hline \multicolumn{2}{|c|}{ Coeff. of var. $\left(\frac{100 \sigma}{\bar{x}}\right)$} & $38 \%$ & & $41 \%$ \\
\hline \multicolumn{2}{|c|}{ Stan. error mean $\left(\sigma_{x}\right)$} & \pm 44.4 & & \pm 25.6 \\
\hline
\end{tabular}

* Absorption coefficient $=$ mgm. absorbed $/ 30 \mathrm{~min} . / \mathrm{sq}$. meter body surface.

the speed of this recovery varied, as demonstrated above.

\section{Effect of hyperglycemia and of insulin-induced hypoglycemia on the absorption of glucose and methionine}

The effect of hyperglycemia on the absorption rates was studied in three subjects. The procedure was to perform one control test, and after an interval of 20 to 30 minutes, an intravenous injection of $50 \mathrm{cc}$. of 50 per cent glucose was given and, immediately afterward, the second absorption test was begun. Capillary blood sugar determinations were made at the beginning and end of each 30-minute test. In one subject (A. B.) 5 per cent glucose and 0.25 per cent methionine was used and in another (M. M.) 5 per cent glucose was used alone. In the third subject (L. E.) 10 per cent glucose and 0.50 per cent methionine was studied. Two of the subjects had the tube located in the usual region of the upper small bowel. The third subject (M. M.) had an ileostomy and the tube was lowered into the ileum so that the distal balloon was just proximal to the ileostomy. Because values for absorption rate in this case represent ileal absorptive capacity, they are not included in the tables. The results obtained in these three experiments are shown in Figure 3. Despite the fact that the average blood sugar level during the second test is considerably higher than during the first, the percentage of change in absorption of glucose and methionine is well within the range of normal variation between two tests as illustrated in Figure 2.

In three additional subjects the influence of insulin-induced hypoglycemia on the absorption rates was studied. The procedure here was to perform one control test and, after an interval of 20 to 30 minutes, the subject was given an intravenous injection of insulin. Fifteen minutes later, the

TABLE V

Absorption rates for approximately 0.50 per cent methionine

\begin{tabular}{|c|c|c|c|c|}
\hline Subject & $\begin{array}{l}\text { Conc. test } \\
\text { sol. } \\
\text { gm. } \%\end{array}$ & $\begin{array}{l}\text { Mgm. meth. } \\
\text { absorbed } \\
30 \mathrm{~min} .\end{array}$ & $\begin{array}{l}\% \text { meth. } \\
\text { absorbed }\end{array}$ & $\begin{array}{l}\text { Meth. } \\
\text { absorption } \\
\text { coefficient }\end{array}$ \\
\hline P. S. & .60 & 912 & 54 & 480 \\
\hline D. M. & .65 & $\begin{array}{r}983 \\
1451\end{array}$ & $\begin{array}{l}56 \\
79\end{array}$ & $\begin{array}{l}485 \\
715\end{array}$ \\
\hline C. T. & .45 & 470 & 39 & 264 \\
\hline J. G. & .55 & $\begin{array}{l}1398 \\
1400\end{array}$ & $\begin{array}{l}94 \\
83\end{array}$ & $\begin{array}{l}700 \\
700\end{array}$ \\
\hline J. L. & .50 & $\begin{array}{l}1148 \\
1096\end{array}$ & $\begin{array}{l}72 \\
71\end{array}$ & $\begin{array}{l}605 \\
575\end{array}$ \\
\hline S. B. & .60 & 486 & 28 & 270 \\
\hline L. E. & .50 & $\begin{array}{r}1237 \\
994\end{array}$ & $\begin{array}{l}84 \\
74\end{array}$ & $\begin{array}{l}805 \\
650\end{array}$ \\
\hline K. M. & .50 & 900 & 59 & 409 \\
\hline \multicolumn{2}{|l|}{ Range } & $470-1451$ & 28-94 & $264-805$ \\
\hline \multicolumn{2}{|l|}{$\overline{\operatorname{Mean}(\overline{\mathrm{X}})}$} & 1040 & 66 & 555 \\
\hline \multicolumn{2}{|c|}{ Stan. dev. $(\sigma)$} & \pm 384 & & \pm 176 \\
\hline \multicolumn{2}{|c|}{ Coeff. of var. $\left(\frac{100 \sigma}{\bar{x}}\right)$} & $37 \%$ & & $32 \%$ \\
\hline \multicolumn{2}{|c|}{ Stan. error mean $\left(\sigma_{x}\right)$} & \pm 110.7 & & \pm 50.8 \\
\hline
\end{tabular}



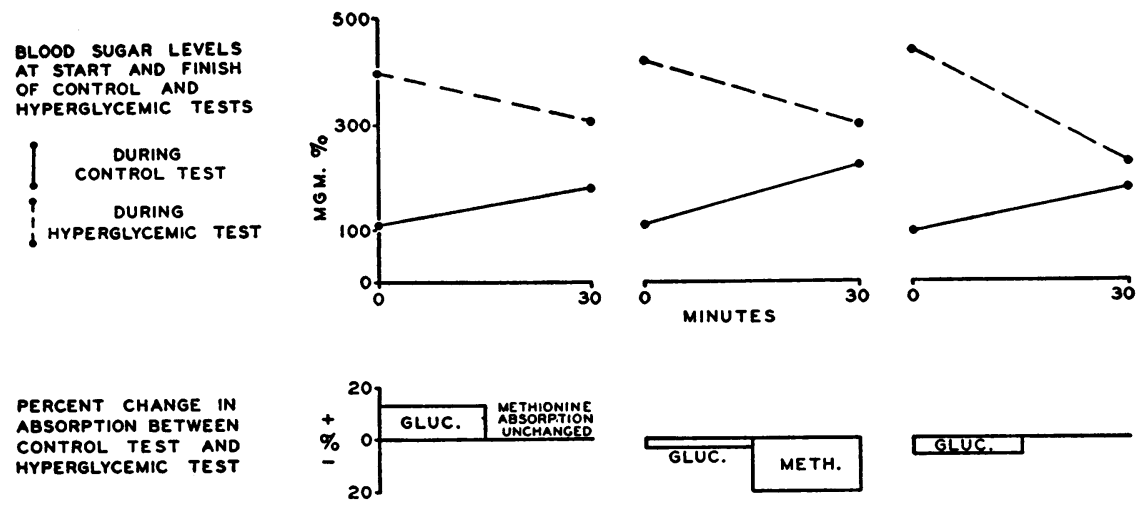

AMOUNTS ABSORBED DURING CONTROL AND HYPERGLYCEMIC TESTS

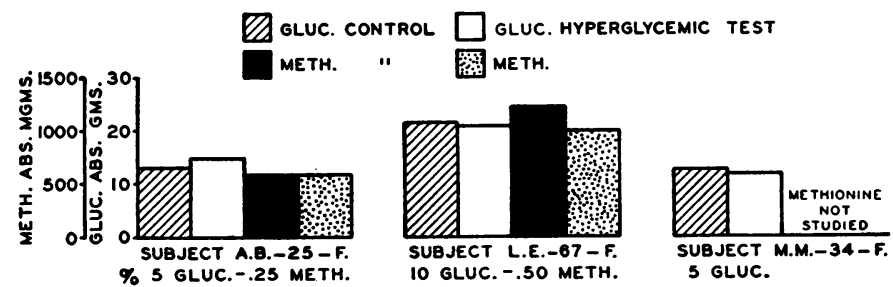

Fig. 3. Effect of Hyperglycemia on Absorption Rates of Glucose and METHIONINE

second absorption test was begun. Blood sugar determinations were made in both tests as indicated in Figure 4. In all cases 5 per cent glucose and 0.25 per cent methionine was used. One subject (R. Q.) was given 20 units of regular insulin, the other two subjects were given 25 units. It is apparent that, although a considerable fall in blood sugar occurred during the second tests, the changes in glucose and methionine absorption rates are again within the normal range of variation.
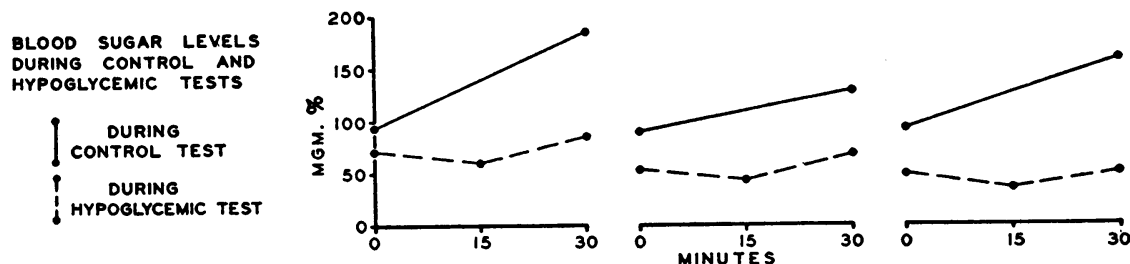

PERCENT CHANGE IN ABS ORPTION BETWEEN CONTROL TEST AND HYPO GLYCEMIC TEST
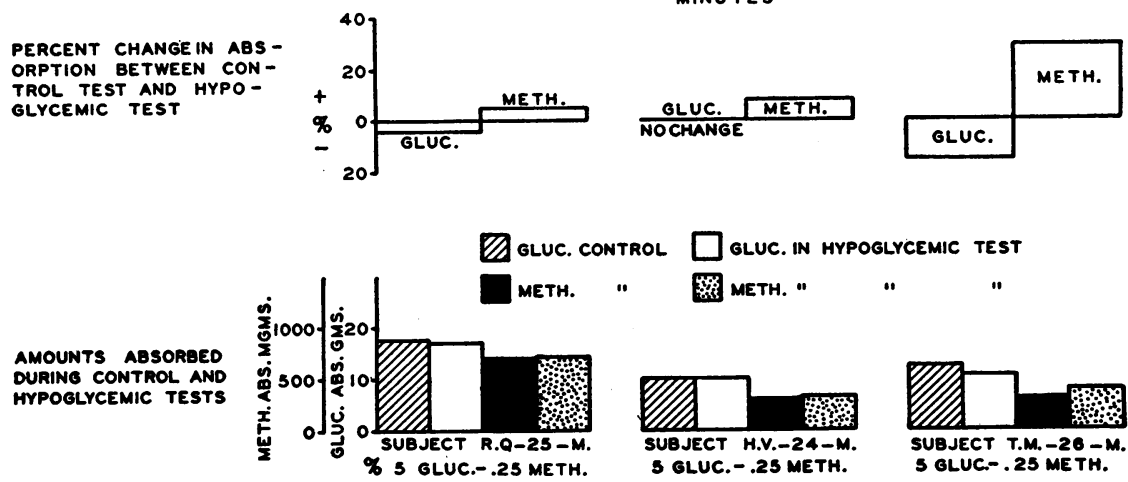

Fig. 4. Effect of Hypoglycemia on Absorption Rates of Glucose and 


\section{DISCUSSION}

Experience with the study of human small bowel absorption using the Nicholson-Chornock principle demonstrates that it is a practical procedure which can be used in investigations of certain aspects of absorption, but that it has definite technical and physiological limitations. From the standpoint of the technique itself, the procedure leaves several variables, which can be only partially controlled. Movement of the tube along the bowel (or the bowel along the tube), seems to be an uncontrollable variable so that the segment of bowel being studied is not necessarily always the same. Since the comparative absorption rates of various levels of the small bowel in man have not been adequately studied, the effect of this factor is unknown. Although we have not directly observed this, it also seems highly probable that, at times, the bowel may "telescope" along the tube, thus presenting an absorbing surface greater than the 45 $\mathrm{cm}$. interval between the tube fenestrations would indicate. The difficulties in obtaining a sharp end-point to the procedure naturally tend to destroy the accuracy of assigning a given absorption value to a set period of time. This lack of sharp end-point has been quite closely correlated with sluggish bowel motility.

Despite these technical objections, the procedure does seem to duplicate physiologic conditions more closely than other previous direct methods of absorption study, and, in our experiments, the reproducibility of results in two consecutive tests has been gratifying. The variation between two tests for glucose has been about 25 per cent, and for methionine about 50 per cent; yet the range in absorption rates from subject to subject is much higher. We are thus forced to the conclusion that the main factor in this marked variability is not the fault of the technique itself, but is rather due to actual absorptive differences among individuals (13). From the practical standpoint of the investigator these results would appear to indicate that the method is of chief use in studying those aspects of absorption which can be varied between two consecutive tests.

Cori's original studies of glucose absorption in rats (14) showed that the absorption rate was constant for solutions of from 25 per cent to 80 per cent. This work formed the basis for the so- called "Cori's law" to the effect that the absorption rate of sugars is independent of their concentration. Hewitt (15), also studying rats, has shown that for very dilute solutions (below 5 per cent) the rate varies directly with the concentration. Studying this problem in the human being, Abbott, Karr, and Miller (5) have demonstrated a similar phenomenon for glucose concentrations of below 5 per cent and Groen ( 7 ) has shown, in a few cases, that there is a direct relationship of concentration to absorption rate up to about 10 per cent, and that over this concentration the rate remains about the same. He did not study a sufficient number of cases, however, to do more than suggest this relationship. Our experiments with two different concentrations of glucose and methionine have been of sufficient number to show a statistically significant greater rate of absorption for the more concentrated solutions. It is apparent, then, that for the range of concentration of glucose naturally occurring in the human small bowel (5), "Cori's Law" does not apply, and that absorption of glucose can be enhanced by increasing its concentration from 5 to 10 per cent. This same phenomenon applies to the representative amino acid methionine in the solution strengths studied. In this connection, it is interesting to speculate on a possible contributing factor in the poor absorption in sprue. The hypomotility of the bowel in sprue, including the stomach in some cases, is well known $(16,17)$. Warren and his co-workers (18) have shown that the stomach dilutes hypertonic sugar solutions before releasing them into the duodenum. It seems plausible to assume, therefore, that delayed gastric emptying in sprue may sufficiently dilute ingested foodstuffs to present to the small bowel a concentration below optimum for maximal absorption. Perhaps lending credence to this speculation is the observation by May and McCreary (17) that the glucose tolerance curve in children with celiac disease could sometimes be improved by delivering the glucose directly into the small bowel by duodenal tube. That the intestine itself, however, exhibits a deficient absorption rate in sprue has been shown in one subject by Groen (19) and in two subjects in the course of our studies.

No previous direct observations on the absorption of methionine from the human small bowel 
seem to have been carried out. Althausen and his associates $(20,21)$ have employed methionine tolerance tests in studying the effects of massive bowel resection on human intestinal absorptive capacity, and Chase and Lewis (22) and Hess (23) have studied directly methionine absorption from the bowel of rats. In none of these studies has the effect of varying concentrations on absorption rate of this amino acid been observed.

In our six experiments wherein the effect of variation in blood sugar was studied, no direct influence of hyperglycemia or hypoglycemia on absorption could be demonstrated. Since the magnitude of the change would have to be more than 25 per cent for glucose or 50 per cent for methionine for its appreciation, it is possible that small changes in absorption may have occurred which are within the error of the method. In this connection, Cori (24) has demonstrated in rats that insulin administration increased the absorption rate for glucose by only about 6 per cent. Were the processes of absorption concerned only with diffusion, it might be expected that the relatively minor changes in blood glucose levels produced here would scarcely alter the gradient between the relatively enormous concentration in the bowel lumen and that in the blood perfusing the mucosa. Since we know that glucose, at least, is absorbed by an active process, it does not seem unreasonable to expect a change in absorption rate depending on body need as reflected by blood concentrations. Our results indicate, however, that the intestinal mucosa does not alter significantly its absorption of glucose with depression or elevation in the blood sugar level. Likewise, Nicholson and Chornock (9) found no difference in the absorptive rate for ascorbic acid between individuals with low and high plasma values for this vitamin, and Mosely and Chornock (25) failed to demonstrate any reduction in galactose absorption following the previous administration of glucose.

\section{SUMMARY AND CONCLUSIONS}

1. An evaluation of the Nicholson-Chornock procedure for the study of human small bowel absorption is reported, based on its use in eighteen subjects for the study of glucose and methionine absorption. The technique appears to be of definite value in the investigation of certain aspects of absorption, but has several sources of error which limit its usefulness.

2. The variability in results between two consecutively run tests in seven subjects was under 25 per cent for glucose and 50 per cent for methionine. The variability in results from individual to individual is several times as large, suggesting that the greatest contributing factor in such a range lies in variation in the absorptive capacity of the intestine itself and not in technical difficulties involved in performing the test.

3. The chief investigative use of the procedure, therefore, seems to lie in the study of those influences on absorption which can be varied between two consecutively performed tests, rather than in comparing absorption rates in one control group with those in another experimental group.

4. The mean rate of glucose absorption by a 45 $\mathrm{cm}$. segment of upper small bowel in man for a 30-minute period, under the conditions of our procedure, is $12.9 \mathrm{gm}$. from a 5 per cent solution, and $19.1 \mathrm{gm}$. from a 10 per cent solution. Similar rates for $d l$-methionine are $454 \mathrm{mgm}$. for a 0.25 per cent solution, and $1,040 \mathrm{mgm}$. for a 0.50 per cent solution. These differences are both statistically significant and disprove the application of "Cori's law" to the absorption of glucose in the range of concentrations naturally occurring in the human intestine.

5. Within the limits of sensitivity of the procedure no detectable influence on the absorption rate of glucose or methionine could be demonstrated by elevating the blood sugar with intravenous glucose or reducing it with insulin.

\section{ACKNOWLEDGMENT}

The author wishes to express his gratitude to Dr. Thomas P. Almy for his many valuable suggestions and constant encouragement, and to Miss Louise Wallace for technical assistance.

\section{REFERENCES}

1. Verzar, F., and McDougall, E., Absorption from the Intestine. Longmans, Green and Co., London, 1936.

2. Sherlock, S., and Walshe, V., The use of a portal anastomotic vein for absorption studies in man. Clin. Sc., 1946, 6, 113.

3. Billings, F. T., Jr., and DePree, H. E., Diagnosis of portal vein obstruction: studies of intestinal absorption of glucose using abdominal collateral veins. Bull. Johns Hopkins Hosp., 1949, 85, 183. 
4. Bean, W. B., Franklin, M., Embick, J. F., and Daum, K., Absorption studies using portal anastomotic veins. J. Clin. Invest., 1951, 30, 263.

5. Abbott, W. O., Karr, W. G., and Miller, T. G., Intubation studies of the human small intestine. VII. Factors concerned in absorption of glucose from the jejunum and ileum. Am. J. Digest. Dis., 1938, 4, 742.

6. Abbott, W. O., and Miller, T. G., Intubation studies of the human small intestine. III. A technic for the collection of pure intestinal secretion and for the study of intestinal absorption. J.A.M.A., 1936, 106, 16.

7. Groen, J., The absorption of hexoses from the upper part of the small intestine in man. J. Clin. Invest., 1937, 16, 245.

8. Miller, T. G., Intubation studies of the human small intestine. XXIV. A review of a ten year experience. Gastroenterology, 1944, 3, 141.

9. Nicholson, J. T. L., and Chornock, F. W., Intubation studies of the human small intestine. XXII. An improved technique for the study of absorption; its application to ascorbic acid. J. Clin. Invest., 1942, 21, 505.

10. Karr, W. G., and Abbott, W. O., Intubation studies of the human small intestine. IV. Chemical characteristics of the intestinal contents in the fasting state and as influenced by the administration of acids, of alkalies, and of water. J. Clin. Invest., $1935,14,893$.

11. Hess, W. C., and Sullivan, M. X., The cysteine, cystine, and methionine content of proteins. J. Biol. Chem., 1943, 151, 635.

12. Nelson, N., A photometric adaptation of the Somogyi method for the determination of glucose. J. Biol. Chem., 1944, 153, 375.

13. Abbott, W. O., Karr, W. G., Glenn, P. M., and Warren, $R$., Intubation studies of the human small intestine. XIV. The absorption of glucose from the duodenum. Am. J. M. Sc., 1940, 200, 532.

14. Cori, C. F., The fate of sugar in the animal body. I. The rate of absorption of hexoses and pentoses from the intestinal tract. J. Biol. Chem., 1925, 66, 691.

15. Hewitt, J. A., The metabolism of carbohydrates. Part III. The absorption of glucose, fructose, and galactose from the small intestine. Biochem. J., 1924, 18, 161.

16. Bockus, H. L., Gastroenterology. W. B. Saunders Co., Philadelphia, 1944.

17. May, C. D., and McCreary, J. F., The glucose tolerance test in celiac disease; significance of low blood sugar curves. J. Pediat., 1940, 17, 143.

18. Warren, R., Karr, W. G., Hoffman, O. D., and Abbott, W. O., Intubation studies of the human small intestine. XV. The absorption and expulsion of glucose from the stomach. Am. J. M. Sc., 1940, 200, 639.

19. Groen, J., The absorption of glucose from the small intestine in deficiency disease. New England J. Med., 1938, 218, 247.

20. Althausen, T. L., Uyeyama, K., and Simpson, R. G., Digestion and absorption after massive resection of the small intestine. I. Utilization of food from a "natural" versus a "synthetic" diet and a comparison of intestinal absorption tests with nutritional balance studies in a patient with only $45 \mathrm{~cm}$. of small intestine. Gastroenterology, 1949, 12, 795.

21. Althausen, T. L., Doig, R. K., Uyeyama, K., and Weiden, $\mathrm{S}$., Digestion and absorption after massive resection of the small intestine. II. Recovery of the absorptive function as shown by intestinal absorption tests in two patients and a consideration of compensatory mechanisms. Gastroenterology, 1950, 16, 126.

22. Chase, B. W., and Lewis, H. B., The metabolism of sulfur. XX. The rate of absorption of $d l$-methionine from the gastrointestinal tract of the white rat. J. Biol. Chem., 1933, 101, 735.

23. Hess, W. C., Rates of absorption and the formation of liver glycogen by methionine, cystine, and cysteine. J. Biol. Chem., 1949, 181, 23.

24. Cori, C. F., The fate of sugar in the animal body. VIII. The influence of insulin on the utilization of glucose, fructose, and dihydroxyacetone. J. Biol. Chem., 1928, 76, 755.

25. Moseley, V., and Chornock, F. W., Intubation studies of the human small intestine. XXV. The absorption of galactose from the intestine of normal individuals and thyrotoxic patients. J. Clin. Invest., 1947, 26, 11. 